\title{
INDICADORES ECONÔMICOS DE QUALIDADE DO LEITE EM UNIDADE DE PRODUÇÃO LEITEIRA
}

Recebido: 07/07/2015

DANELUZ, Marina Oliveira ${ }^{1}$; BONATTO, Camila Beatriz ${ }^{2}$; GONZÁLEZ, Helenice de Lima ${ }^{3}$; FERNANDES, Flávia Fontana ${ }^{4}$; CANEVER, Mário Duarte ${ }^{5}$.

${ }^{1}$ Médica Veterinária, Mestranda em Desenvolvimento Territorial e Sistemas Agroindustriais; ${ }^{2}$ Acadêmica, Faculdade de Veterinária, UFPEL; ${ }^{3}$ Professora Adjunta, Departamento de Veterinária Preventiva, UFPEL;

${ }^{4}$ Professora Adjunta, Departamento de Solos, FAEM/UFPEL; ${ }^{5}$ Professor, Departamento de Ciências Sociais Agrárias, FAEM/UFPEL.

\section{RESUMO}

$\mathrm{O}$ s parâmetros estabelecidos pela Instrução Normativa MAPA no 62 para comercialização de leite cru refrigerado garantem maior qualidade do produto final a ser comercializado. Para tanto, dentro do sistema de produção leiteira, são necessários investimentos em saúde animal que auxiliem na remuneração do produtor. 0 presente trabalho objetivou demonstrar quantitativamente as despesas relacionadas com o controle de qualidade através da Contagem de Células Somáticas (CCS) e Contagem Bacteriana Total (CBT) e a relação desses indicadores com o preço pago pela indústria como forma de bonificação. Realizaram-se visitas mensais a uma propriedade localizada no município de Pelotas, nos anos de 2012 e 2013, sendo coletados valores provenientes das notas fiscais do leite referentes às bonificações pagas ao produtor. Realizou-se ainda a tabulação de dados referentes ao custo de produção e análise de indicadores econômicos. 0 valor médio anual pago pela indústria à propriedade no ano de 2012 foi de $R \$ 0,7154$ por litro de leite e a bonificação por qualidade foi de $\mathrm{R} \$ 0,1025$ por litro de leite. No ano de 2013, o valor pago foi de $\mathrm{R} \$ \mathbf{0 , 8 2 8 1}$ por litro e a bonificação foi de $\mathrm{R} \$ \mathbf{0 , 1 2 2 5}$ por litro. $\mathrm{O}$ investimento em produtos e processos visando aumentar a qualidade do leite representou, no ano de $2012,3,6 \%$ do custo total e, no ano de $2013,8,7 \%$ do custo total do sistema de produção. O retorno obtido foi de $R \$ 2,71$ e $R \$ 1,86$ nos anos de 2012 e 2013, respectivamente, para cada real investido em melhorias na qualidade do leite, demonstrando a viabilidade do investimento.

Palavras-chave: Bonificação. Bovinocultura Leiteira. Higiene da ordenha. 


\section{INTRODUÇÃO}

A atividade leiteira apresenta um dos maiores potenciais de crescimento para a próxima década em relação aos principais produtos do agronegócio brasileiro. As taxas de crescimento projetadas indicam um incremento de 2,6 a 3,4\% na produção anual. As projeções nacionais para o ano de 2016 situam-se próximas dos 37 bilhões de litros, mantendo o Brasil como $3^{\circ}$ produtor mundial de leite (BRASIL, 2014).

O leite, por natureza, é um alimento rico em nutrientes. Sua qualidade é um dos temas mais discutidos atualmente dentro do cenário nacional de produção leiteira. Dessa forma, a saúde da glândula mamária, a higiene da ordenha, o ambiente em que a vaca fica alojada e os procedimentos de limpeza do equipamento de ordenha são fatores que afetam diretamente a contaminação microbiana do leite cru (SANTOS; FONSECA, 2001).

A indústria do leite necessita atender inúmeros requisitos de ordem técnica para comercializar seus produtos no mercado interno e externo, além da necessidade de contemplar um consumidor que a cada dia torna-se mais exigente. Nesse cenário, o Ministério da Agricultura, Pecuária e Abastecimento (MAPA), publicou a Instrução Normativa no 62 (BRASIL, 2011) que atualizou alguns aspectos da Instrução Normativa MAPA no 51, de 18 de setembro de 2002, e aprovou o novo Regulamento Técnico de produção, identidade e qualidade dos leites tipo A, cru refrigerado e pasteurizado, além do Regulamento Técnico da coleta de leite cru refrigerado e seu transporte a granel. Em vista disso, a conscientização e a capacitação dos produtores são fundamentais para aumentar a quantidade e a qualidade do leite produzido no Brasil, buscando destaque no mercado nacional e mundial (MARCÍLIO, 2008).

A atividade produtiva primária é o segmento mais vulnerável da cadeia agroindustrial devido às limitações tecnológicas e gerenciais. Por não conseguir controlar o preço do produto que vende, o produtor necessita administrar as variáveis que estão sob o seu controle. Trata-se de uma estratégia para tornar o produto competitivo, atingindo menores custos de produção. Com isso, dentro do sistema de produção leiteiro são necessários investimentos em nutrição, sanidade, produtos de higiene e limpeza, medicamentos, manutenção de 
equipamentos de ordenha, que venham a auxiliar e agregar melhores características ao leite produzido (REIS et al., 2001).

O pagamento por qualidade não depende de novas normas, uma vez que estes programas consistem no pagamento de bonificação para o produtor que fornece a matéria-prima com características diferenciadas, o que gera retorno para a indústria e consumidor. Isto se configura essencialmente como um acordo entre fornecedor e comprador, devendo, todavia, ser consideradas as várias peculiaridades de cada indústria e de cada região (SANTOS, 2005).

Os parâmetros de qualidade são cada vez mais utilizados para detecção de falhas nas práticas de manejo, servindo como referência na valorização da matéria-prima (NORO et al., 2006). A Contagem de Células Somáticas (CCS) de animais individuais e/ou do rebanho é um parâmetro utilizado para verificar o índice de mastite (RIBEIRO, 2008). Outro indicador de qualidade muito significativo é a Contagem Bacteriana Total (CBT) que reflete as condições higiênicas da produção e de armazenamento do leite (MÜLLER, 2002).

O leite pode ser contaminado quando entra em contato com a superfície de equipamentos e/ou utensílios de ordenha, assim como no próprio tanque de refrigeração do leite. A contagem bacteriana total do leite pode aumentar significativamente quando este entra em contato com equipamentos nos quais a limpeza e sanitização são deficientes, pois os microorganismos proliferam nos resíduos de leite presentes em recipientes, borrachas, junções e qualquer outro local onde ocorra acúmulo desses resíduos (GUERREIRO, et al., 2005).

Para que haja a remuneração por qualidade adequada, as condições de retirada do leite, armazenamento e cuidados com a sanidade animal são fundamentais. Faz-se necessário ainda, dentro do sistema de produção leiteiro, o conhecimento dos custos de produção, os quais vêm se tornando cada vez mais importantes na administração rural para determinação da eficiência de produção e planejamento das empresas rurais (MARTIN et al., 1994).

Alguns entraves que desaceleram o processo de informatização e gestão econômica, como a pouca difusão do uso da informática entre os agricultores, em especial na pequena propriedade, o alto custo de softwares específicos e a falta de assessoramento técnico, ainda perduram. Porém, cada vez mais, a adoção de ferramentas de informática na gestão 
das empresas agropecuárias torna-se uma realidade. Dados sobre custos de produção têm sido utilizados para muitas finalidades e podem servir também para análise de indicadores econômicos e dos recursos empregados numa atividade produtiva, útil ao processo de tomada de decisão do produtor, como por exemplo no controle de qualidade do produto final (MARTIN et al., 1994).

Em vista da importância da valorização do produto final dentro de um sistema de produção leiteiro e da necessidade do conhecimento dos indicadores econômicos, objetivou-se demonstrar quantitativamente as despesas relacionadas com o controle de qualidade do leite, bem como a relação desses indicadores com o preço pago pela indústria como forma de bonificação e o retorno do capital investido para tal atividade em uma propriedade leiteira da região sul do Rio Grande do Sul.

\section{RELATO DE CASO}

Realizaram-se visitas mensais a uma propriedade pertencente ao Projeto de Extensão e Desenvolvimento da Bovinocultura Leiteira da Região Sul do Rio Grande do Sul (PDBL), localizada no município de Pelotas, durante os anos de 2012 e 2013. A propriedade possui aproximadamente 19 hectares destinados à produção de leite e utiliza ordenha mecanizada no sistema de balde ao pé. A mão de obra é familiar e são realizadas, durante o manejo da ordenha, técnicas de pré-dipping e pós-dipping, bem como o Teste da Caneca de Fundo Preto, diariamente, e o California Mastitis Test (CMT), quinzenalmente.

Além da aplicação de questionário sobre o manejo realizado na propriedade, foram coletados dados referentes aos valores recebidos pela remuneração por qualidade e higiene do leite, obtidos diretamente das notas fiscais apresentadas pelo produtor. O valor da bonificação pela venda do leite foi calculado através da fórmula: (preço médio pago por bonificação X média de litros de leite vendidos) X 12 meses. A Indústria bonifica o criador (reais por litro) avaliando a higiene e a qualidade do leite através da análise da média de dois indicadores: Contagem de Células Somáticas (CCS) e Contagem Bacteriana Total (CBT).

Realizou-se ainda a tabulação de dados referentes ao fluxo de caixa da propriedade, incluindo o custo de produção total (que abrange gastos com: alimentação do rebanho, inseminação artificial, produção de forrageiras, energia elétrica, vacinações, mão de obra, 
medicamentos, impostos, taxas e serviços contratados, entre outros, englobando custos fixos e variáveis) e custos relacionados ao investimento com medidas de higiene e limpeza requeridas pelo sistema de produção (produtos utilizados no pré e pós-dipping, papel toalha, detergentes para higienização dos equipamentos de ordenha e antimicrobianos de uso intramamário utilizados nas vacas no período seco). Para o cálculo do retorno do investimento utilizou-se a seguinte fórmula: receita pela bonificação ( $R \$$ ) / custo com medidas de higiene e limpeza (R\$).

\section{RESULTADOS E DISCUSSÃO}

Durante o período estudado o preço pago pelo litro do leite aumentou gradativamente ao longo dos meses, havendo pequenas oscilações em algumas épocas do ano, o que de acordo com Frigon et al. (1999) é esperado, quando há uma perfeita transmissão das oscilações de preço, em curto espaço de tempo e na mesma proporção.

Conforme a Tabela 1, o valor médio anual pago pela indústria para a propriedade em questão no ano de 2012 foi de R\$ 0,7154 por litro de leite e a média anual paga como bonificação por qualidade foi de $\mathrm{R} \$$ 0,1025 por litro, representando $14,3 \%$ do total do valor médio do litro de leite.

Tabela 1 - Contagem de Células Somáticas (CCS), Contagem Bacteriana Total (CBT) e a bonificação por esses parâmetros de qualidade, em propriedade leiteira, no ano de 2012.

\begin{tabular}{cccccc}
\hline $\begin{array}{c}\text { (2012) } \\
\text { Mês }\end{array}$ & $\begin{array}{c}\text { CCS } \\
\text { (cél./ml) }\end{array}$ & $\begin{array}{c}\text { CBT } \\
\text { (UFC/ml) }\end{array}$ & $\begin{array}{c}\text { Bonificação } \\
\text { (R\$/I) }\end{array}$ & $\begin{array}{c}\text { Litros } \\
\text { Vendidos }\end{array}$ & $\begin{array}{c}\text { Valor litro } \\
\text { (R\$/I) }\end{array}$ \\
\hline Janeiro & 210.000 & 24.000 & 0,110 & 5.484 & 0,7135 \\
Fevereiro & 387.000 & 17.000 & 0,110 & 5.635 & 0,7140 \\
Março & 287.000 & 21.000 & 0,100 & 5.905 & 0,7045 \\
Abril & 371.000 & 11.000 & 0,090 & 4.960 & 0,6928 \\
Maio & 326.000 & 31.000 & 0,090 & 4.473 & 0,7155 \\
Junho & 149.000 & 16.000 & 0,090 & 4.389 & 0,7160 \\
Julho & 337.000 & 13.000 & 0,100 & 4.483 & 0,7260 \\
Agosto & 323.000 & 10.000 & 0,100 & 5.093 & 0,7065 \\
Setembro & 197.000 & 1.000 & 0,100 & 5.155 & 0,7060 \\
Outubro & 147.000 & 108.000 & 0,115 & 6.151 & 0,7195 \\
Novembro & 159.000 & 67.000 & 0,110 & 5.899 & 0,7330 \\
Dezembro & 212.000 & 15.000 & 0,115 & 6.512 & 0,7370 \\
\hline Médias: & $\mathbf{2 5 8 . 7 5 0}$ & $\mathbf{2 7 . 8 3 3}$ & $\mathbf{0 , 1 0 2 5}$ & $\mathbf{5 . 3 4 5}$ & $\mathbf{0 , 7 1 5 4}$ \\
\hline
\end{tabular}


Em relação ao fluxo de caixa da propriedade em 2012, o investimento em medidas de prevenção e controle da mastite (produtos de higiene e limpeza, práticas de pré e pósdipping, medicamentos, detergentes ácidos e alcalinos) representou 3,6\% do custo total do sistema de produção $(R \$ 67.059,66)$ ou seja, $R \$ 2.427,56$.

No ano de 2013 (Tabela 2), o valor médio anual pago pela indústria foi de $\mathrm{R} \$ \mathbf{0 , 8 2 8 1}$ por litro, e o valor médio anual pago como bonificação foi de $\mathrm{R} \$$ 0,1225 por litro, representando $14,8 \%$ do preço pago. Em relação ao investimento em medidas de higiene e qualidade do leite, este representou $8,7 \%$ ( $R \$ 4.698,57$ ) do custo total ( $R \$ 54.030,62$ ), demonstrando maior investimento no setor de higiene e limpeza neste ano.

Tabela 2 - Contagem de Células Somáticas (CCS), Contagem Bacteriana Total (CBT) e a bonificação por esses parâmetros de qualidade, em propriedade leiteira, no ano de 2013.

\begin{tabular}{cccccc}
\hline $\begin{array}{c}\text { (2013) } \\
\text { Mês }\end{array}$ & $\begin{array}{c}\text { CCS } \\
\text { (cél./ml) }\end{array}$ & $\begin{array}{c}\text { CBT } \\
\text { (UFC/ml) }\end{array}$ & $\begin{array}{c}\text { Bonificação } \\
\text { (R\$/I) }\end{array}$ & $\begin{array}{c}\text { Litros } \\
\text { Vendidos }\end{array}$ & $\begin{array}{c}\text { Valor litro } \\
\text { (R\$/I) }\end{array}$ \\
\hline Janeiro & 377.500 & 41.500 & 0,115 & 6.145 & 0,7520 \\
Fevereiro & 75.500 & 78.000 & 0,100 & 5.478 & 0,7250 \\
Março & 242.500 & 27.500 & 0,090 & 4.027 & 0,7550 \\
Abril & 342.500 & 19.500 & 0,070 & 2.873 & 0,7550 \\
Maio & 403.500 & 18.500 & 0,085 & 3.497 & 0,7750 \\
Junho & 293.500 & 65.000 & 0,095 & 4.090 & 0,7950 \\
Julho & 242.000 & 20.500 & 0,095 & 4.958, & 0,8250 \\
Agosto & 216.000 & 3.500 & 0,120 & 5.921 & 0,8550 \\
Setembro & 195.000 & 15.000 & 0,135 & 8.325 & 0,8850 \\
Outubro & 167.500 & 21.000 & 0,195 & 8.505 & 0,9450 \\
Novembro & 242.000 & 6.000 & 0,185 & 8.279 & 0,9350 \\
Dezembro & 293.500 & 42.500 & 0,185 & 9.373 & 0,9350 \\
\hline Médias & $\mathbf{2 5 7 . 5 8 3}$ & $\mathbf{2 9 . 8 7 5}$ & $\mathbf{0 , 1 2 2 5}$ & $\mathbf{5 . 9 5 6}$ & $\mathbf{0 , 8 2 8 1}$ \\
\hline
\end{tabular}

A contagem de células somáticas no leite bovino é usada como um indicador da qualidade do leite e, indiretamente, da produção higiênica do leite (SMITH, 1996). A contagem bacteriana total é um indicador extremamente fidedigno em relação à higienização de instalações, equipamentos, tanques de expansão e práticas adotadas durante a ordenha (SUZIN et al., 2013). Neste estudo, esses dois indicadores mantiveram-se dentro dos parâmetros recomendados pela Instrução Normativa MAPA no 62 para a produção de um leite de qualidade. 
A Tabela 3 demonstra o retorno dos investimentos empregados na melhoria da qualidade do leite. No ano de 2012, foi de $R \$ 2,71$ para cada real investido e, em 2013, foi de $R \$ 1,86$. A receita anual pela bonificação foi calculada multiplicando-se a quantidade de litros de leite vendidos (média anual) pelo valor da bonificação (média anual) por 12 meses.

Tabela 3 - Médias de produção de leite (litros vendidos), bonificação, preço pago pelo litro de leite e receita obtida com a bonificação nos anos de 2012 e 2013.

\begin{tabular}{lcccc}
\hline Litros vendidos & $\begin{array}{c}\text { Bonificação } \\
\text { (R\$/I) }\end{array}$ & $\begin{array}{c}\text { Preço pago } \\
\text { (R\$/I) }\end{array}$ & $\begin{array}{c}\text { Receita pela } \\
\text { Bonificação } \\
\text { (R\$/ano) }\end{array}$ \\
\hline $\mathbf{2 0 1 2}$ & 5.345 & 0,1025 & 0,7154 & $\mathrm{R} \$ 6.574,35$ \\
$\mathbf{2 0 1 3}$ & 5.956 & 0,1225 & 0,8281 & $\mathrm{R} \$ 8.755,32$ \\
\hline
\end{tabular}

Os valores encontrados no presente estudo demonstram a importância de investimentos em práticas de higiene, prevenção e controle da mastite para obtenção de melhores resultados em relação aos indicadores de qualidade do leite e, com isso, gerar um aumento na receita bruta da atividade, obtida através da comercialização de leite de boa qualidade.

Outro aspecto a ser abordado é a importância do conhecimento do desempenho econômico da atividade produtiva, resultando na tomada de decisões seguras quanto à viabilidade de práticas e investimentos a serem implantados na propriedade.

\section{CONCLUSÃO}

$\mathrm{Na}$ propriedade estudada, nos anos de 2012 e 2013, o investimento em produtos e tecnologias para proporcionar maior higiene e qualidade do leite cru refrigerado gerou um aumento significativo no preço pago por litro de leite vendido. O retorno do investimento econômico, percebido através da bonificação por qualidade, foi favorável e satisfatório. 


\section{ECONOMIC INDICATORS OF MILK QUALITY IN A PRODUCTION UNIT}

\section{ABSTRACT}

T

he parameters established by MAPA Normative Instruction $\mathrm{n}$ - 62 for the commerce of refrigerated raw milk ensure higher quality of the final product. For this, the dairy production system requires investment in animal health to remunerate the producer. This study aimed to demonstrate quantitatively the costs related to quality control through the Somatic Cell Count (SCC) and Total Bacterial Count (TBC) and the relationship of these indicators with the price paid by the industry as a form of bonus. Monthly visits to a farm located in the city of Pelotas were performed in 2012 and 2013. Values related to the bonuses paid to the producer were collected from invoices. Tabulation of the data about the cost of production and analysis of economic indicators were also performed. The annual average amount paid by the industry in 2012 was $\mathrm{R} \$ 0.7154$ per liter of milk and the bonus paid for quality was $\mathrm{R} \$ 0.1025$. In 2013 , the average price paid was $\mathrm{R} \$ 0.8281$, and the average amount paid as a bonus was $R \$ 0.1225$. The investment in products and processes for the improvement of milk quality in 2012 represented $3.6 \%$ of the total cost, and in 2013, $8.7 \%$ of the total cost of the production system. The return obtained was $R \$ 2.71$ and $R \$$ 1.86, in 2012 and 2013 respectively, for every real spent with improvements for milk quality, demonstrating the viability of this investment.

Keywords: Bonus. Dairy cattle. Milking hygiene.

\section{INDICADORES ECONÓMICOS DE LA CALIDAD DE LA LECHE EN UNIDAD DE PRODUCCIÓN LECHERA}

\section{RESUMEN}

os parámetros establecidos por la Instrucción Normativa no 62 para la comercialización de leche cruda refrigerada garantiza una mayor calidad del producto final que se desea comercializar. Con este fin, dentro del sistema de producción de leche son necesarios inversiones en sanidad animal para ayudar en el rendimiento del productor. Este estudio tuvo como objetivo demostrar cuantitativamente los gastos relacionados con el control de calidad a través del Recuento de células somáticas (RCS) y Recuento bacteriológico total (RBT) y la relación de estos indicadores al precio pagado por la industria como una forma de subsidio. Se realizaron visitas mensuales en una propiedad ubicada en el municipio de Pelotas, en los años 2012 y 2013, siendo registrados los valores obtenidos de la leche de las facturas correspondientes a los bonos pagados al productor. También se hizo la tabulación de los datos sobre el costo de producción y análisis de indicadores económicos. El monto promedio pagado por la industria de la propiedad en el 2012 fue de $\mathrm{R} \$ 0,7154$ por litro de leche y el bono anual promedio pagado como por la calidad fue de $R \$ 0,1025$. Para el año 
2013 , el precio medio pagado fue de $\mathrm{R} \$ 0,8281$, y el monto promedio pagado como extra $\mathrm{R} \$$ 0,1225. La inversión en las medidas de calidad de la leche en 2012 representó el 3,6\% del costo total, y en 2013 , el 8,7\% del coste total del sistema de producción, obtener retorno de $\mathrm{R} \$ 2,71$ y $\mathrm{R} \$ 1,86$, los años 2012 y 2013, respectivamente, por cada dólar invertido en mejoras en la calidad de la leche, lo que demuestra la viabilidad de la inversión en la calidad de la leche.

Palabras clave: Bono. Ganado lechero. Higiene del ordeño.

\section{REFERÊNCIAS}

BRASIL. Ministério da Agricultura, Pecuária e Abastecimento. Instrução Normativa no 62, de 29 de dezembro de 2011. Diário Oficial, 30 dez. 2011. Seção 1.

BRASIL. Ministério da Agricultura, Pecuária e Abastecimento. Projeções do Agronegócio: Brasil 2013/2014 a 2023/2024, Projeções de Longo Prazo. 5. ed. Brasília: MAPA/ACS, 2014. 100 .

FRIGON, M.; DOYON, M.; ROMAIN, R. Asymetry in farm-retail price transmission in the northeastern fluid milk market. Food Marketing Policy Center, Research Report, n. 45, University of Connecticut, May 1999.

GUERREIRO, P. K.; MACHADO, M. R. F.; BRAGA, G, C.; et al. Qualidade microbiológica de leite em função de técnicas profiláticas no manejo de produção. Ciência e Agrotecnologia, Lavras, v. 29, n. 1, p. 216-222, jan./fev. 2005.

MARCÍLIO, T. Qualidade do leite. Florianópolis: UCB, 2008. 73p. Monografia (Especialização em Higiene e Inspeção de Produtos de Origem Animal), Universidade Castelo Branco, 2008.

MARTIN, N. B.; SERRA, R. ANTUNES, J. F. G.; et al. Custos: Sistema de Custo de Produção Agrícola. Informações Econômicas, São Paulo, v. 24, n. 9, p. 97-122, 1994. Disponível em: <ftp://ftp.sp.gov.br/ftpiea/tec1-0994.pdf> Acesso em: 15 mai. 2014.

MÜLLER, E. E. Qualidade do leite, células somáticas e prevenção da mastite. In: SUL - LEITE: SIMPÓSIO SOBRE SUSTENTABILIDADE DA PECUÁRIA LEITEIRA NA REGIÃO SUL DO BRASIL, 2, 2002, Maringá. RESUMOS. Maringá: UEM/CCA/DZO - NUPEL, 2002. p. 117-206.

NORO, G.; GONZÁLEZ, F. H. D.; CAMPOS, R.; et al. Fatores ambientais que afetam a produção e a composição do leite em rebanhos assistidos por cooperativas no Rio Grande do Sul.

Revista Brasileira de Zootecnia, v. 35, n. 3, p. 1129-1135, 2006.

REIS, R. P.; MEDEIROS, A. L.; MONTEIRO, L. A.; Custos de produção da atividade leiteira na região sul de Minas. Organizações Rurais \& Agroindustriais. v. 3, n. 2 (2001). Disponível em: 
http://revista.dae.ufla.br/index.php/ora/article/viewArticle/272> Acesso em 12 de abr. de 2014.

RIBEIRO, J. N. Qualidade e segurança na produção de leite cru em Portugal e na Europa. In: CONGRESSO BRASILEIRO DE QUALIDADE DO LEITE, 3, 2008, Recife. RESUMOS. Recife: CCS Gráfica e Editora, 2008. p. 175-181.

SANTOS, M. V.; FONSECA, L. F. L. Importância e efeito de bactérias psicrotróficas sobre a qualidade do leite. Revista Higiene Alimentar, São Paulo, v. 15, n. 82, p. 13-19, 2001.

SANTOS, M. V. Utilizando a CCS e a CBT como ferramenta em tempos de pagamento por qualidade do leite. In: CARVALHO, M. P.; SANTOS, M. V. (Org.). Estratégia e competitividade na cadeia de produção de leite. Passo Fundo: Berthier, 2005, p. 246-260.

SMITH, K. L. Standards for somatic cells in milk: physiological and regulatory. Mastitis Newsletter, v. 21, p. 7-9, 1996.

SUZIN, G. O.; DANELUZ, M. O.; ALVES, B. F.; et al. Indicadores econômicos, preço pago por litro de leite e sua relação com a contagem de células somáticas (CCS) e contagem bacteriana total (CBT) em unidade de produção localizada no município de Pelotas (RS). In: SIMPÓSIO DO LEITE, 10, 2013, Erechim. RESUMOS. Erechim: II Mostra de Trabalhos Científicos, 2013.

Autor para correspondência: Marina Oliveira Daneluz. Departamento de Ciências Sociais Agrárias. Universidade Federal de Pelotas. Campus Universitário. Capão do Leão (RS). CP. 354, CEP 96010-900. maridaneluz22@gmail.com 